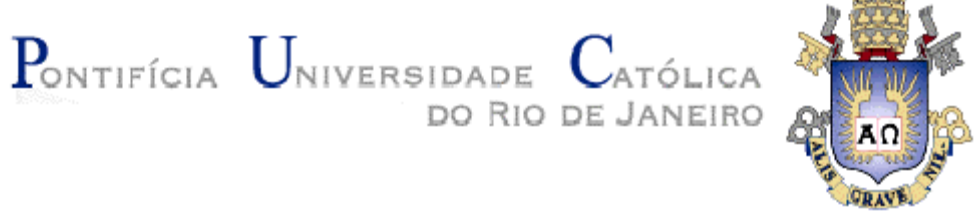

Susana Beatriz Sacavino

\title{
Educação em/para os Direitos Humanos em processos de democratização: \\ o caso do Chile e do Brasil
}

Tese de Doutorado

Tese apresentada ao Programa de Pós-Graduação em Educação do Departamento de Educação da PUC-Rio como parte dos requisitos parciais para obtenção do título de Doutor em Educação.

Orientador: Prof. Ralph Ings Bannell

Rio de Janeiro

Abril de 2008 
Susana Beatriz Sacavino

Educação em/para os Direitos Humanos em processos de democratização:

o caso do Chile e do Brasil

Tese apresentada como requisito parcial para obtenção do título de Doutor pelo Programa de Pós-Graduação em Educação do Departamento de Educação do Centro de Teologia e Ciências Humanas da PUC-Rio. Aprovada pela Comissão Examinadora abaixo assinada.

Prof. Ralph Ings Bannell

Orientador

Departamento de Educação - PUC-Rio

Profa. Vera Maria Ferrão Candau Departamento de Educação - PUC-Rio

Profa $^{a}$. Angela Maria de Randolpho Paiva

Departamento de Sociologia - PUC-Rio

Prof ${ }^{a}$ Roseli Fischmann

USP

Prof ${ }^{a}$. Sabrina Moehlecke

UFRJ

Prof. Paulo Fernando C. de Andrade

Coordenador Setorial do Centro de

Teologia e Ciências Humanas

Rio de Janeiro, 18 de abril de 2008 
Todos os direitos reservados. É proibida a reprodução total ou parcial do trabalho sem autorização da universidade, da autora e do orientador.

\section{Susana Beatriz Sacavino}

Possui graduação em Ciencias Politicas y Relaciones Internacionales - Universidad Catolica de Cordoba (1982), mestrado em Ciências Jurídicas pela Pontifícia Universidade Católica do Rio de Janeiro (1989) e doutorado em Educação pela Pontifícia Universidade Católica do Rio de Janeiro (2008). Atualmente é diretora da Revista Novamerica - Nuevamerica e da organização não governamental (ONG) - Novamerica, com sede no Rio de Janeiro. Tem experiência na área de Ciência Política, com ênfase em Cidadania, Educação e Direitos Humanos, atuando principalmente nos seguintes temas: formação de educadores, educação em direitos humanos, educação e cidadania, oficinas pedagógicas e gestão institucional.

Ficha Catalográfica

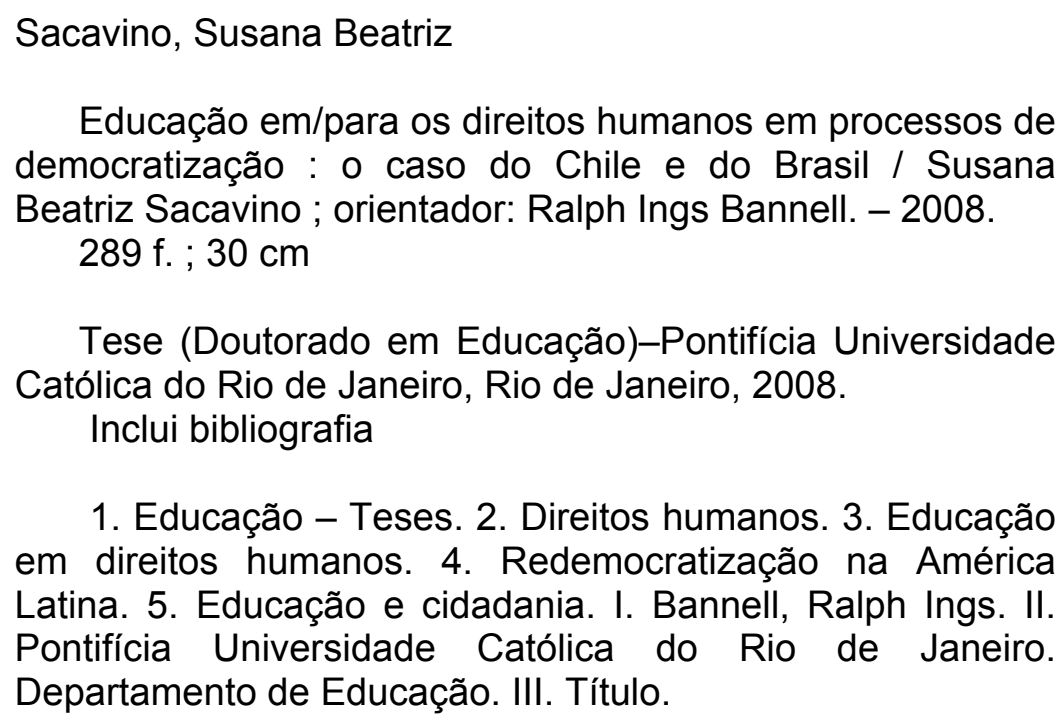

1. Educação - Teses. 2. Direitos humanos. 3. Educação em direitos humanos. 4. Redemocratização na América Latina. 5. Educação e cidadania. I. Bannell, Ralph Ings. II. Pontifícia Universidade Católica do Rio de Janeiro. Departamento de Educação. III. Título. 


\section{Agradecimentos}

Ao professor Ralph Bannell, pela orientação, apoio e confiança, fundamentais para todas as etapas deste trabalho.

Aos entrevistados e entrevistadas, que generosamente contribuíram com seus conhecimentos e experiências de vida para a realização desta pesquisa.

À professora Vera Candau, pelo estímulo, apoio e partilha de conhecimentos. E aos colegas do GECEC [Grupo de Estudos sobre Cotidiano, Educação e Cultura(s)] .

A meu amigo Jorge Osorio, por seus múltiplos apoios para a realização da pesquisa no Chile.

À equipe da Novamerica, pelo espaço estimulante de partilha de sonhos, conhecimentos e amizade e a solidariedade sempre oportuna.

À PUC-Rio que me concedeu uma bolsa que tornou possível este estudo.

A minha família: Eli, minha mãe, Néstor, Gisela, Teresa e Malaquías, pelo carinho, paciência e confiança incondicionais e pelo que significam na minha vida.

A minhas amigas e amigos, que o tempo todo foram uma presença próxima, dispostas/os a colaborar, entender, acompanhar e sempre incentivar. 


\section{Resumo}

Sacavino, Susana Beatriz; Bannell, Ralph Ings. Educação em/para os direitos humanos em processos de democratização: o caso do Chile e do Brasil. Rio de Janeiro, 2008, 289 p. Tese de Doutorado - Departamento de Educação, Pontifícia Universidade Católica do Rio de Janeiro.

A década de 1980 na América Latina se caracteriza pelo fim das ditaduras em vários países do continente e o início de processos de redemocratização. Nesse contexto, inicia-se a educação em/para os direitos humanos, que envolveu no seu processo de desenvolvimento diferentes sujeitos históricos, indivíduos, grupos e instituições de diversos tipos, especialmente ONGs. A presença do Estado e a elaboração de políticas públicas também foram progressivamente se afirmando. A tese aborda essa temática a partir da compreensão da evolução da educação em/para os direitos humanos na América Latina, tendo presente seu desenvolvimento no contexto internacional. Analisa as inter-relações entre o papel dos diferentes atores sociais, organizações não-governamentais e outras instituições da sociedade civil, governo etc. na promoção da educação em/para os direitos humanos em contextos sociopolíticos de redemocratização. Nesse sentido, apresenta dois estudos de caso - Chile e Brasil -, privilegiando, do ponto de vista metodológico, entrevistas realizadas com profissionais que tiveram participação ativa nesse processo. Discute as principais questões e desafios para o desenvolvimento da educação em/para os direitos humanos no momento atual do continente.

\section{Palavras-chave:}

Direitos humanos; educação em direitos humanos; redemocratização na América Latina; educação e cidadania. 


\section{Abstract}

Sacavino, Susana Beatriz; Bannell, Ralph Ings (Advisor). Human rights education in democratization processes: the Chilean and Brazilian cases. Rio de Janeiro, 2008, 289 p. Thesis - Departamento de Educação, Pontifícia Universidade Católica do Rio de Janeiro.

The 1980s in Latin America were marked by the fall of dictatorial regimes in many countries in the continent and by the installation of redemocratization processes. Within this context, human rights education emerged. Its development process involved different historical subjects, individuals, groups and different types of institutions, specially non-governmental organizations. State presence and the elaboration of public policies steadily increased. This thesis investigates the theme with the objective of understanding the evolution of human rights education in Latin America, focusing on its development in the international context. It analyses the inter-relationship between the roles of different social actors, non-governmental agencies organizations and other civil society or governmental institutions etc. in promoting human rights education in sociopolitical redemocratization contexts. In order to accomplish this, two case studies are presented - Chile and Brazil. Special emphasis is given to interviews carried out with professionals who were actively involved in the process. It also discusses the main questions and challenges faced by human rights education in the continent today.

\section{Keywords}

Human rights; human rights education; Latin America redemocratization; education; citizenship. 


\section{Sumário}

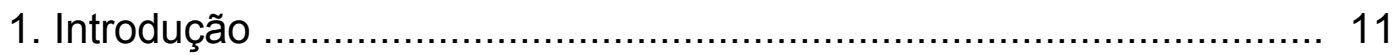

1.1. Nosso interesse pelo tema ....................................................... 11

1.2. Delimitação do tema: processos de democratização e educação em/para os direitos humanos ...................................................... 15

1.3. Questões, hipótese de trabalho e objetivos da pesquisa ................ 21

1.4. Situando a pesquisa de campo: considerações metodológicas ...... 25

2. Direitos humanos e educação: um caminho em construção .............. 33

2.1. Direitos humanos: um discurso vazio? ........................................ 33

2.1.1. Direitos humanos como tema global ........................................ 34

2.1.2. Globalização/es e direitos humanos ........................................ 39

2.1.3. Direitos humanos: entre a modernidade e a pós-modernidade .... 44

2.1.4. Direitos humanos: novas dimensões e desafios ......................... 53

2.1.4.1. Miséria e exclusão: violação da dignidade humana ................... 54

2.1.4.2. Discriminação, xenofobia e racismo ...................................... 55

2.1.4.3. Terrorismo, crime organizado e corrupção: ameaças aos direitos humanos, à democracia e à paz .......................................... 56

2.1.4.4. Novos desafios para a ciência e a tecnologia ......................... 57

2.1.4.5. A tensão entre direitos da igualdade e direitos da diferença ..... 59

2.2. Direitos humanos pós-11 de setembro de 2001 ........................... 61

3. Educação em/para os direitos humanos: uma construção histórica ... 64

3.1. A educação em/para os direitos humanos nos instrumentos

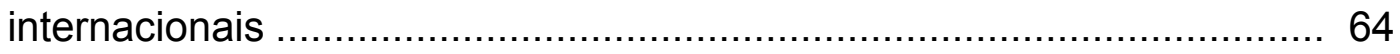

3.2. Educação em/para os direitos humanos na América Latina ........... 72

3.2.1. A educação em/para os direitos humanos na década de 80 ....... 73

3.2.2. A educação em/para os direitos humanos na década de 90 ....... 79

3.2.3. Principais organismos internacionais presentes no desenvolvimento da educação em/para os direitos humanos na

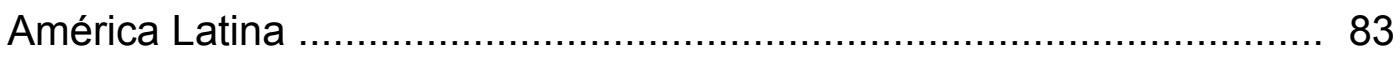


3.3. A identidade da educação em/para os direitos humanos: um processo em construção 90

4. Direitos humanos e educação na América Latina: estudos de caso .. 100

4.1. Tecendo a historia, articulando o presente: o caso chileno ............ 100

4.1.1. Direitos humanos e processo de democratização ....................... 101

4.1.2. Processo da educação em/para os direitos humanos no Chile .... 113

4.2. O significado da educação em/para os direitos humanos: a ótica dos atores

4.2.1. "A educação em direitos humanos é um processo de toda uma vida [...] forma parte de nossa convicção, de nossa consciência".

4.2.2. "Educar em direitos humanos, é gerar um processo, uma construção coletiva do que significa a dignidade humana".

4.2.3. "Há algo que há que trabalhar e potenciar: as redes"

4.2.4. "Educação em/para os direitos humanos como tema transversal.

O fato de ser lei tem um peso".

4.2.5. "Os direitos humanos são o coração da democracia".

4.2.6. "Não podemos ficar tranqüilos enquanto há índices de pobreza que escandalosamente contrastam com os índices de riqueza de alguns poucos..."

4.2.7. "Direitos de igualdade e da diferença: sim e não. No nível formal sim, há instrumentos para isso; no nível cotidiano, não".

4.2.8. "No caso do Chile temos estado muito sós".

4.3. Democratização e educação em/para os direitos humanos: avanços, dificuldades e desafios

5. Tecendo a historia, articulando o presente: o caso brasileiro …......... 165

5.1. Direitos humanos e processo de democratização ......................... 165

5.2. Educação em/para os direitos humanos no Brasil ........................ 177

5.3. O significado da educação em/para os direitos humanos: a ótica dos atores 188

5.3.1. Direitos humanos: "um terreno em que vamos trabalhar sempre"

5.3.2. "Eu acho que houve uma evolução, mas ainda tem muito 
caminho a percorrer"

5.3.3. No campo da educação em direitos humanos "os atores governamentais [...] são importantes e a interlocução dessa multiplicidade da sociedade civil com estes atores governamentais às vezes é meio complicada, meio contraditória mas ao mesmo tempo ela pode dar bons frutos"

5.3.4. "Sem democracia não temos direitos humanos e sem direitos humanos não temos democracia"

5.3.5. "No fundo os desafios estão ligados ao desafio da questão democrática"

5.3.6. "Parece-me que não dá mais para pensar igualdade e diferença como coisas separadas [...] são complementares"

5.3.7. "Mudar as mentalidades é uma tarefa importante da educação em direitos humanos"

5.4. Democratização e Educação em/para os Direitos Humanos: avanços, dificuldades e desafios

6. Considerações finais: educação em/para os direitos humanos na América Latina: tensões, sonhos, perspectivas ................................... 226

6.1. Avanço na legislação - efetivação de direitos .............................. 230

6.2. Sociedade civil - políticas públicas ........................................... 233

6.3. Educação em/para os direitos humanos - diferentes concepções .. 236

6.4. Educação para a formação de sujeitos de direito e para o empoderamento - educação para o mercado

6.5. Difusão/sensibilização - aprofundamento nos processos formativos

6.6. Direitos da igualdade - direitos da diferença 246

7. Referências Bibliográficas 249 Anexos 


\section{Lista de abreviaturas}

$A B I$ - Associação Brasileira de Imprensa

ANDHEP - Associação Nacional de Direitos Humanos, Pesquisa e Pósgraduação

ANPEd - Associação Nacional de Pós-Graduação e Pesquisa em Educação

CEAAL - Consejo de Educación de Adultos de América Latina

CIDE - Centro de Investigación y Desarrollo de la Educación

CODEPU - Comité de Defensa de los Derechos del Pueblo

CNT - Comando Nacional de Trabajadores

DESC - Direitos Econômicos, Sociais e Culturais

DHNET - Rede de Direitos Humanos e Cultura

ECO - Comisión Chilena de Derechos Humanos, Educación y Comunicaciones

FASE - Federação de Órgãos para Assistência Social e Educacional

FASIC - Fundación de Ayuda Social de las Iglesias Cristianas

FOSIS - Fondo de Solidaridad e Inversión

GATS - Acordo Geral sobre o Comércio de Serviços

GAJOP - Gabinete de Assessoria Jurídica às Organizações Populares

IBASE - Instituto Brasileiro de Análises Sociais

IIDH - Instituto Interamericano de Derechos Humanos

IPEDEHP - Instituto Peruano de Educación en Derechos Humanos y la

Paz

MEDH - Movimento de Educadores/as em/para os Direitos Humanos

MJDH - Movimento Justiça e Direitos Humanos

MRC - Movimento de Reorientação Curricular

OAB - Ordem dos Advogados do Brasil

OEA - Organização dos Estados Americanos

OFCMO - Marco Curricular de los Objetivos Fundamentales y Contenidos

Mínimos Obligatorios

OFT - Objetivos Fundamentales Transversales

ONGs - Organizações Não-Governamentais

ONU - Organização das Nações Unidas

PRAIS - Programa de Reparación y Atención Integral de Salud para las víctimas de violaciones de derechos humanos

PIIE - Programa Interdisciplinário de Investigaciones en Educación

PNEDH - Plano Nacional de Educação em Direitos Humanos

PNDH - Programa Nacional de Direitos Humanos I

PNDH II - Programa Nacional de Direitos Humanos II

PNUD - Programa das Nações Unidas para o Desenvolvimento

RCNEI - Referencial Curricular Nacional para Escola Indígena

SBPC - Sociedade Brasileira para o Progresso da Ciência

SEPPIR - Secretaria Especial de Políticas de Promoção da Igualdade

Racial

SERPAJ - Serviço de Paz e Justiça

SPM - Secretaria Especial de Políticas para as Mulheres

UNESCO - Organização das Nações Unidas para a Educação, a Ciência e a Cultura 